SECCIÓN INFORMATIVA 



\section{NOTICIARIO INTERNACIONAL}

\section{PRESENTACIÓN}

Estamos viviendo momentos inéditos, desafiantes, imprevistos e imprevisibles. De entre todas las cosas que nos quitó la pandemia, están los numerosos encuentros académicos que se tenían programados y que tuvieron que ser cancelados.

Nos vimos en medio de una pelea desigual con un enemigo invisible, el más rudo e infame y queda demostrado que somos buenos luchadores, que por lo menos en el tema académico.

Es destacable como todas las organizaciones gremiales, académicas y otras instituciones han decidido asumir el reto de utilizar la tecnología para realizar sus proyectos y generar la mayor cantidad de oportunidades de aprendizaje, que se pretende reflejar en la presente sección informativa.

Confiamos en que la vida nos dará la oportunidad de volver, de juntarnos otra vez, de volver al trabajo, a la academia, al encuentro con los amigos, a los congresos.

Homenaje al Doctor Desiderio Sanabria

Desde esta sección informativa rendimos un sentido homenaje de admiración y respeto al que en vida fuera comprometido miembro de AIDA PARAGUAY y del CILA, apasionado por el seguro y por la academia.

Un Amigo que todos recuerdan con afecto por ser una persona muy especial, por su calidez, por su calidad humana, por el amor a su Patria, a su familia, a sus amigos y por el talento musical.

Hacemos llegar la sentida palabra de condolencia a su familia y a la sección paraguaya de AIDA, esperando que su recuerdo inspire a las nuevas generaciones.

\section{NOTICIAS DEL CILA}

El comité Ibero latinoamericano de AIDA, CILA convocó a todas las secciones y grupos de trabajo para que realicen actividades virtuales y como resultado se tuvo una gran cantidad de seminarios virtuales, sesiones y webinars como los que se detallan a continuación. 


\section{Sesiones de grupos de trabajo.}

\section{Reaseguro}

Presidente: Rebeca Herrera Colombia

Vicepresidente: Martin Argañaraz Luque Argentina

Secretario Fernando Hurtado de Mendoza Perú

Tema: EI COVID -19 y su impacto en el contrato de reaseguro a partir de la aplicación del principio de comunidad de suerte ante potenciales condenas para el pago de pérdidas de ingresos o utilidades por mala aplicación de los amparos de Interrupción de Negocio. 8 de junio de 2020.

\section{Conferencistas}

Rebeca Herrera Díaz; Fernando Hurtado de Mendoza; Sergio Ruy Barroso de Mello; Carlos Estebenet; Martín Argañaraz Luque; Pablo Medina Magallanes.

\section{Resolución de disputas}

Presidente Luis Sandoval Chile

Vicepresidente Gregorio Garro Argentina

Secretario Pablo Medina Magallanes México

Tema: El Ombudsman en Seguros, experiencias comparadas y factibilidad de implementarlo en Latinoamérica. 30 de junio de 2020.

\section{Conferencistas}

Chirstoper Rodd; Fernando Pérez; Rolando Eyzaguirre; Miguel De La fuente.

\section{Responsabilidad civil}

Presidente: Gabriel Vivas Colombia

Vicepresidente: Jonathan Gómez Colombia

Secretario: Miguel Ángel de la Fuente México

\section{Financial lines}

Presidente Ricardo Peralta Chile

Secretario Patricio Mangialardi Argentina

Se llevaron a cabo dos sesiones conjuntas de los grupos de Responsabilidad civil y grupos financieros. 
Tema: Reunión Conjunta de los Grupos de Trabajo de Líneas Financieras y de Responsabilidad Civil del CILA-14de julio de 2020.

\section{Conferencistas}

María Fabiana Compiani; Nicolás Uribe Lozada; Mariana Ferraz Menescal.

Tema: Análisis del Proyecto del Código Unificado de Colombia: Reformas al régimen de la responsabilidad civil y del contrato de seguro desde la perspectiva del Derecho Comparado. 29 de octubre de 2020.

\section{Conferencistas}

Prof. Dr. Miquel Martín Casals; Prof. Dr. Gabriel Jaime Vivas Díez

Moderador: Dr. Marcio Malfatti.

\section{Seguro de automotores}

Presidente: Marcelo Barreto Leal Brasil

Vicepresidente: Daniel Alejandro Russo Argentina

Secretario: Andrea Medina Perú

Tema: Seguro de Automóviles y el impacto de la pandemia - 20 de agosto de 2020.

\section{Conferencistas}

Martín Cassaza; Giulio Valz Gen; Angelica Carlini

\section{Seguro de crédito y caución}

Presidente: Francisco Artigas Chile

Vicepresidente: Marcio Malfati Brasil

Secretario: Santiago Toribio Argentina

Tema Credit, Surety and Political Risk (re-) insurance. Challenges \& opportunities in COVID 19 times.

\section{Conferencista}

Jan Mueller

Tema Seguro de caución a primer requerimiento.

\section{Conferencista}

Gastón Esquivel 


\section{Principios generales del contrato de seguro}

Presidente: Alonso Núñez del Prado Perú

Vicepresidente: Roberto Ríos Chile

Secretaria: Berta Furrer Argentina

Tema: la función del seguro - 12de noviembre de 2020.

\section{Conferencista}

Dr. Abel Veiga Copo

Tema: El principio de razonabilidad y las expectativas del asegurado-12de noviembre de 2020.

\section{Conferencista}

Dr. Alonso Núñez del Prado Simons

Quedan pendientes de realización las sesiones virtuales ampliadas de los siguientes grupos de trabajo.

\section{Seguro de vida, pensiones y seguros colectivos}

Presidente: Ivy Cassa Brasil

Vicepresidente: Carlos Facal Argentina

Secretaria: Zuni Benavente Paraguay

\section{Nuevas tecnologias, prevención y seguros}

Presidente: Andrea Signorino Uruguay

Vicepresidente: Félix Benito Osma España

Secretario: Marianella Melgar Uruguay

\section{Comercialización de seguros}

Presidente: Sandra Ramírez Bolivia

Vicepresidente: Neftalí Garro Costa Rica

Secretaria: Carola Hidalgo Bolivia

\section{Cambio climático}

Presidente Hilda Esperanza Colombia

Vicepresidente: Pery Saraiva Brasil

Secretario: María Kavana Brasil 


\section{Cumulo de prestaciones y subrogación}

Presidente Enrique Quintana Argentina

Vicepresidente Sandra Antola Paraguay

Secretario Héctor Jaime Giraldo Colombia

\section{Seguros de transporte y maritimos}

Presidente: Juan Guillermo Hincapié Colombia

Vicepresidente: Darcio da Mota Brasil

Secretario: Leandro Vidal Uruguay

\section{Supervisión de seguros}

Presidente: Eberhard von Lucken Paraguay

Vicepresidente: Fabiana Compiani Argentina

Secretario: Myriam Aragón Perú

\section{Fraude en seguros}

Presidente: Ana Rita Petraroli Brasil

Vicepresidente: Florencia Mangialardi argentina

Secretario: Nora Claros Bolivia

Las sesiones de grupos de trabajo del CILA, pueden ser vistas en video en el canal YouTube de ACOLDESE link https://www.youtube.com/results?search_query=aCOLDESE,

\section{PRESENTACIÓN LIBER AMICORUM RUBEN STIGLITZ}

Fue un hecho trascendental y un motivo de satisfacción para el CILA la edición y presentación el libro Derecho de Seguros Liber Amicorum (el libro de los amigos) en homenaje al Maestro, Rubén Stigliz. Por lo que en la presente sección se transcribe parte del discurso de presentación de los directores de la obra.

"En el convencimiento de que a la memoria de un estudioso, un Maestro tan reconocido y un escritor tan preclaro, solo se le puede rendir homenaje con lo que a él más le hubiera gustado, con una ofrenda colectiva de trabajo de estudio y de ciencia jurídica.

Un homenaje, de sentimientos compartidos de admiración, de respeto, de afecto y, sobre todo, de gratitud.

De admiración por todo lo que estudió, por todo lo que aprendió y, sobre todo, por todo lo que enseñó con tanta generosidad, y autoridad intelectual, por sus obras mo- 
numentales de numerosos tomos, varias veces actualizadas por el noble interés de que sus lectores, sin excepción, siempre tuvieran una última y enriquecida versión.

El respeto profundo por la seriedad con la que era capaz de abordar todos los temas del Derecho privado en general y del seguro en particular; al fin y al cabo, nada de lo que decía, hacía o proponía era superficial, trivial y sin fundamento.

El afecto por ser lo que era, pero principalmente por ser como era, un erudito con la sencillez que caracteriza a los grandes y la mente abierta de los verdaderos sabios que nunca dejan de aprender, y de 'reinventarse'. Dueño de tantos títulos, con todo merecimiento era llamado doctor, profesor, maestro, tratadista, etc. y él, en su humilde nobleza, prefería ser llamado "Lito", así su prestigio fuera internacional, y sus aportes reconocidos, apreciados y aplaudidos por estudiosos, doctrinarios, estudiantes y los más renombrados académicos del orbe.

Es también un homenaje de inmensa gratitud de quienes lo conocemos y lo queremos, así en presente, porque así estará siempre vigente e inmortal en la memoria de sus alumnos y en el corazón de sus amigos.

Nos dolió su partida; no por él, que ahora está en el descanso eterno en un lugar sin dolor, sin enfermedad y sin penas, en la paz que solo Dios puede dar. Nos duele su ausencia por la falta que le hace a su familia, a la ciencia, al Derecho privado, especialmente al Seguro, a la justicia, a su gente, y a nosotros que lo respetamos, que lo recordamos, que lo admiramos, y lo extrañamos, con afecto imperecedero.

En nuestra mentalidad limitada a lo que es comprensible y entendible para los seres humanos, a veces pudimos cuestionar por qué se van los seres tan importantes y trascendentales, por qué no podría la vida ser proporcional a los merecimientos, así, 'Lito', el Gran Rubén, nunca se hubiera ido.

Como diría François Mauriac, "La muerte no nos roba los seres amados. Al contrario, nos los guarda y nos los inmortaliza en el recuerdo"

Trajo consuelo en el duelo lo escrito por Carlos Alberto Boaglio, "Los hombres que "viven" no se mueren nunca, se duermen de a ratos, de a ratos pequeños, y el sueño infinito es sólo una excusa.

Cuando yo me vaya, extiende tu mano, y estarás conmigo sellada en contacto, y aunque no me veas, y aunque no me palpes, sabrás que por siempre estaré a tu lado.

Entonces, un día, sonriente y vibrante, sabrás que volví para no marcharme”.

La presente obra y sus autores son además el testimonio vivo de que los grandes de verdad, como nuestro querido Lito, viven para siempre en sus obras, en la memoria, en el recuerdo, en el ayer y en el hoy, y en el corazón.

En todo caso, pese a la resignación, nada es y nada será igual sin el Maestro, ni el Derecho, ni el Seguro, ni su querida Argentina, ni nuestra querida AIDA, nuestro CILA, ni las muchas generaciones de sus alumnos, ni su querida familia, ni nosotros sus amigos que tanto lo quisimos; nada permanecerá igual sin él. 
El que hizo tanto y todo lo que hizo, lo hizo tan bien, merece tan sentido y emotivo homenaje, y es un honor para nosotros homenajearlo, una y otra vez.

Agradecemos profundamente a la familia de nuestro querido Lito, a la que tuvimos el honor de conocer a su lado, a su querida esposa, compañera inseparable y amiga, Kety, que también nos honra con su amistad.

A Gabriel, dueño del mismo ADN, y continuador del legado del Maestro, del académico de todos los días, del aprestigiado autor y del caballero.

A toda su familia que nos ha concedido el privilegio de rendir un tributo de amistad y de afecto a quien todo se lo merece.

A IJ EDITORES, que ha puesto a disposición todos sus recursos tecnológicos, logísticos y de difusión para que esta obra tenga el realce y la trascendencia que corresponde al trabajo dedicado de sus autores.

A los autores (más de treinta de diversas nacionalidades), de manera especial, a los amigos de Lito, a los que tanto lo quisieron y con tanto esmero escribieron y enviaron sus artículos, pues sin su generoso aporte esta obra no hubiera fructificado.

En ellos, sin distingo, se percibe la excelencia del contenido y del 'buen hacer', la dedicación en la tarea, el respeto por el lector y la profundidad del afecto por el homenajeado, que en esencia es la verdadera razón de esta obra.

Este es un libro que representa el afecto por el colega que "partió", por el maestro que todavía enseña, el escritor que todavía habla en cada uno de sus libros y el amigo que vive y seguirá viviendo entre nosotros, que todavía, cada vez que lo recordamos nos sonríe y nos abraza. Se siente esa sonrisa y ese abrazo (como dice la canción) "como resolana debajo la piel".

A Lito que descansa en paz, a su memoria eterna que siempre estará con nosotros, dedicamos el presente Liber Amicorum como la mejor manera de decir Gracias Maestro, y de refrendar que sigue y seguirá viviendo.

Un expreso agradecimiento y reconocimiento a los que hicieron posible esta obra a los que tantas horas esmero y estudio dedicaron.

Vamos a nombrarlos a todos con el mismo afecto y reconocimiento que Lito lo hubiera hecho.

- Eduardo Mangialardi y Florencia Mangialardi: Los vehículos autónomos y su aseguramiento.

- María Fabiana Compiani: reflexiones en torno a la citación en garantía del asegurador.

- Carlos José María Facal: El seguro de accidentes personales (ap).

- Gabriel Stiglitz y Ana Claudia Gandolfo de Stiglitz: La obra de Lito.

- Horacio Vita - Roberto M. Pagés LL.: El seguro obligatorio y voluntario automotor en Argentina. 
- María Sandra Ramírez Bernal: El seguro de responsabilidad civil en Bolivia.

- Pablo Heredia: contrato de seguro y reaseguro: quiebra o liquidación de las partes.

- Aida Kemelmajer de Carlucci: Los llamados "daños punitivos” en el derecho del seguro, en la jurisprudencia argentina.

- Sebastián J. Cancio: El seguro en la era del big data.

- Carlos Esteban Jaramillo Mor: Reflexiones en torno al suicidio y su asegurabilidad en el derecho de seguros contemporáneo, evolución histórica y proyección internacional.

- Sergio Mello: Deberes, obligaciones y buena fe de los aseguradores y reaseguradores en el derecho comparado en el contexto de América Latina.

- Paulo Luis de Toledo Piza: Notas sobre el perjuicio a la subrogación del asegurador en el derecho brasileño.

- Marcio Malfatti: Aleatoria es la vida, el seguro es conmutativo.

- Ricardo Bechara Santos: Naturaleza aleatoria del contrato de seguro. la conmutatividad no es de su indole, pese a respetables opiniones contrarias.

- Ernesto Tzirulnik: Ajustamiento de siniestro y reaseguro en la experiencia brasileña.

- María Cristina Isaza Posse: El seguro de responsabilidad civil y la jurisprudencia de la corte suprema de justicia colombiana.

- Alejandro Vigil Iduate: seguros de vida. actualidades y retos.

- Fernando Palacios Sánchez: La asegurabilidad del suicidio, parangón entre la situación colombiana y la argentina.

- Jaime Alberto Arrubla Paucar: Diálogos entre el derecho y la tecnología: la inteligencia artificial, los contratos y la responsabilidad civil.

- Carlos Ignacio Jaramillo: La modificación de las circunstancias en la órbita contractual, y la alteración imprevisible y sobreviniente del estado del riesgo en el contrato de seguro su 'agravación' y su 'disminución'. aspectos generales, nuevas tendencias, e incidencia del 'criterio de la razonabilidad'.

- Abel B. Veiga Copo: Suicidio y aseguramiento.

- José María Muñoz Paredes: La reforma de la ley española de contrato de seguro: oportunidad y alcance.

- José Luis Pérez Serrabona Gonzales: El deber de declaración de la agravación del riesgo durante la vigencia del contrato de seguro como deber de información. 
- Eugenio Llamas Pombo: Evolución y situación del sector bancaseguros en España.

- Javier Pérez Serrabona: Las entidades de seguros ante un nuevo paradigma europeo que protege los derechos e intereses de los usuarios.

- Francisco Javier Tirado Suárez: Las cuestiones de constitucionalidad planteadas en relación con la ley de contrato de seguro.

- Lorenzo Mezzasoma: La insolvencia del consumidor: ¿realidad o utopía?

- Pablo Medina Magallanes: En búsqueda de la real y efectiva protección del consumidor de seguros en México, en el marco del derecho comparado.

- Alonso Núñez del Prado Simons: La causalidad en las pérdidas aseguradas.

- Andrea Signorino Barbat: El contrato de reaseguros en la nueva ley de seguros uruguaya no 19.678 .

- Luis Alberto Meza Carbajal: Equilibrio contractual y protección del asegurado. la experiencia peruana.

- Miguel de la Fuente: Consideraciones legales sobre el seguro de declaraciones y garantías.

EL CILA reconoce y agradece a los autores esperando que el libro sea recibido por la comunidad académica con el mismo afecto con el que se preparó, gracias a la familia de Rubén por aceptar el homenaje, gracias al co-director de la obra Carlos Ignacio Jaramillo J. por la inspiración y fortaleza, Gracias a Julio Levene, a IJEditores y a Todo Su Equipo.

\section{Argentina}

De acuerdo a lo gentilmente informado por la Dra. Fabiana Compiani Presidente de AIDAARGENTINA Las actividades de AIDA Argentina durante el segundo semestre de 2020, fueron las siguientes:

01/08/2020 A cinco meses de la declaración de la pandemia: ¿Impacto realmente al mercado asegurador? Organizado por AEDSIA, con el patrocinio de nuestra asociación siendo disertante el vocal de la CD de AIDA Argentina Dr. Martín Argañaraz Luque, y la moderación de la Dra. Leticia Pelle Delgadillo.

03/08/2020 Neurociencias, Derecho y Seguro, organizado por AIDA ARGENTINA conjuntamente con el Instituto de Derecho del Seguro del Colegio de Abogados de Rosario, miembro correspondiente de nuestra institución. Disertante. Dr. Waldo Sobrino.

12/08/2020 Seguros y Consumidor- La actividad es organizada por el Estudio Pimentel y Asociados de Brasil y cuenta con la disertación del Dr. Marcio Malfatti, del Dr. Adilson Campoy y la Dra. Fabiana Compiani. 
19/08/2020 COVID-19 Efectos económicos en el mercado de Reaseguro. sesión del Grupo de trabajo de Reaseguros de AIDA Internacional, con la participación de nuestro Vicepresidente $1^{\circ}$, Dr. Carlos Estebenet.

20/08/2020 Seguro de automóviles y el impacto de la pandemia, Sesión Virtual del Grupo de Trabajo del CILA, Seguro de Automotores, del que nuestro asociado Daniel Russo es su Vicepresidente, disertación de los Drs. Martín Casazza (Argentina), Giulio Valz-Gen (Perú) y Angélica Carlini (Brasil).

21/08/2020 Consumidor y Seguros, a cargo del Dr. Martín Magula, que se organizada por el Instituto de Derecho de Seguro del Colegio de Abogados de Santa Fe- CASF.

26/08/2020 Webinar Lloyd's: un actor relevante en el mercado asegurador latinoamericano, organizado por ARIAS LATAM, con la exposición de Daniel Revilla en conversación con los Drs. Roberto Ríos y Felipe Hoetz.

29/08/2020 Presentación de la obra "Derecho de Seguros Liber Amicorum en homenaje al maestro Rubén Stiglitz”, en conmemoración al Día del Abogado en Argentina, dirigida por la Dra. María Sandra Ramírez Bernal y el Dr. Carlos Ignacio Jaramillo J. organizado por el Comité Iberolatinoamericano de AIDA - CILA y AIDA internacional.

02/09/2020 Inteligencia Artificial y Seguro. Organizado por el Instituto de Derecho del Seguro del Colegio de Abogados de San Isidro (CASI), miembro correspondiente de nuestra asociación, siendo disertante la Dra. Celeste Colombo.

07/09/2020 Inteligencia artificial. Derecho y Seguro, organizado por el Instituto de Derecho del Seguro del Colegio de Abogados de Rosario, miembro correspondiente de nuestra institución. Disertante. Dr. Waldo Sobrino.

08/09/2020 Reunión mensual de la Subcomisión de Derecho del Seguro de la Asociación de Abogados de Tandil, miembro correspondiente de nuestra asociación. Tema: Derechos de los consumidores y los seguros, el papel de la OMIC en denuncias de terceros.

14/09/2020 Reunión del Instituto del Derecho del Seguro del Colegio de Abogados de San Isidro-CASI-, miembro correspondiente de AIDA Argentina. Tema. "Análisis de la Responsabilidad del Productor Asesor de Seguros a 5 años del CCyC." Disertante: Dr. Héctor Soto.

17/09/2020 Simulación de Arbitraje en vivo, webinar organizado por AIDA EUROPA basado en los principios del contrato de Reaseguro de Aida Mundial.

18/09/2020 Arbitraje y Seguro, organizado por el Instituto de Derecho de Seguros del Colegio de Abogados de Santa Fe. Disertante: Roberto C Hermida.

24/09/2020 La responsabilidad del productor asesor de seguro de acuerdo a la ley de defensa del consumidor. Reunión mensual ampliada de AIDA Joven Argentina. Disertante: Dr. Rodrigo Puértolas.

29/09/2020 Seguro de caución a primer requerimiento. Sesión virtual ampliada del Grupo de Trabajo CILA, Seguro de Crédito y Caución, del que nuestro asociado San- 
tiago Toribio es su Secretario como asimismo uno de los disertantes. Disertantes: Jan Muller (Alemania) y Gastón Esquivel (Argentina).

29/09/2020 Mesa debate. Suma asegurada como límite de cobertura. Análisis de fallo reciente. Organizada por el Instituto de Derecho del Seguro del Colegio de Abogados de Rosario miembro correspondiente de nuestra institución y AIDA JOVEN argentina. Actuarán como moderadores la Dra. María Claudia Rosés y el Dr. Joaquín Hernández.

30/09/2020 Seguro y Pandemia, Panorama a nivel regional, organizado por el Instituto de Derecho de Seguro del Colegio de Abogados de San Isidro (CASI), miembro correspondiente de nuestra asociación. Disertantes. Dr. Roberto Ríos (Chile).

09/10/2020 Traba de Embargos en cuentas de Aseguradoras, su registración, afectación, alcances y utilidad (RGAA 39.1.2.8 y Resol 31773/2007). Reunión del Grupo de Trabajo Supervisión de AIDA ARGENTINA. Se remitió a todos los asociados las conclusiones de dicho grupo sobre el tema Análisis y reinterpretación de las normas que rigen el Proceso de suscripción de seguros.

14/10/2020 Comercialización del Seguro, organizado por el Instituto del Derecho del Seguro del Colegio de Abogados de San Isidro-CASI-, miembro correspondiente de AIDA Argentina. Disertantes: Dra. María Fabiana Compiani y Dr. Héctor Miguel Soto.

15/10/2020 Sesión del Grupo de trabajo de Reaseguros de AIDA Internacional, con la participación de nuestro Vicepresidente $1^{\circ}$, Dr. Carlos Estebenet.

21/10/2020 Propuesta de Seguro y contrato de Seguro (A propósito de un pronunciamiento de la CSJN) organizada por el Instituto de Derecho del Seguro del Colegio de Abogados de Lomas de Zamora, miembro correspondiente de nuestra asociación. Introducción: Oscar Benclowicz, Moderadora: María Teresa Lorenzón. Coordinadora: Patricia Antequera Ríos.

27/10/2020 Contrato de seguro automotor e intereses contrapuestos (Fallo SCBA "Puga") organizado por el Colegio de Abogados de Morón, miembro correspondiente de nuestra asociación. Disertantes: María Fabiana Compiani presidenta de nuestra asociación y Hernán Quadri, secretario de la Cámara de Apelaciones del Dpto. Judicial de Morón. Sala II.

28/10/2020 Seguro y nuevas tecnologías. Jornada Extraordinaria organizada por el Instituto de Derecho del Seguro del Colegio de Abogados de San Isidro (CASI), miembro correspondiente de nuestra asociación. Disertante: Andrea Signorino Barbat, Secretaria General de AIDA mundial.

04/11/2020 Reunión mensual del Grupo de Trabajo Supervisión de AIDA ARGENTINA. Temario: Conclusiones respecto de Traba de Embargos preventivos en cuentas de Aseguradoras y Registro Domicilios electrónicos Poder Judicial Provincia de Bs Aires (Acuerdo 3989 SCBA 21/10/2020).

09/11/2020 Arrepentimiento en la Contratación del Seguro organizado por el Instituto de Derecho del Seguro del Colegio de Abogados de San Isidro (CASI) miembro correspondiente de nuestra asociación. Disertantes: Carlos José María Facal y Gastón Martínez. 
10/11/2020 Derecho de Seguros y Consumo, Jornada organizada por AIDA y AIDA JOVEN. Temario y Disertantes. Consumidores hipervulnerables de seguros, a cargo de Silvina Furlotti; Daños Punitivos, a cargo de Gabriel Stiglitz y Daños punitivos en la actividad aseguradora a cargo de Leandro Rodríguez Pons.

10/11/2020 El Productor Asesor de Seguros, el Contrato de Seguro y el Código Civil y Comercial de la Nación, organizado por el Instituto de Derecho de Seguros del Colegio de Abogados de Lomas de Zamora, miembro correspondiente de nuestra asociación. Introducción: Oscar Benclowicz, Disertante: Héctor Miguel Soto, Moderadora: María Teresa Lorenzón. Coordinadora: Patricia Antequera Ríos.

12/11/2020 Sesión virtual del Grupo de Trabajo de Principios Generales de Derecho de Seguros de CILA, del cual nuestra asociada Berta Paulina Furrer es Secretaria sobre el tema La función del seguro a cargo de Abel Veiga Copo y El principio de razonabilidad y las expectativas del asegurado a cargo del presidente del grupo Alonso Núñez del Prado Simons con la coordinación de su Vicepresidente Roberto Ríos Ossa.

17/11/2020 Y 19/11/2020 Webinar del Grupo de Trabajo de AIDA INTERNACIONAL sobre Líneas Financieras y Cyber Risk.

25/11/2020 Los nuevos Directorios Profesionales en las Compañías de Seguros organizado por el Grupo de Trabajo de Supervisión de AIDA ARGENTINA. Disertante: Guillermo Bolado. Coordinadora: Graciela Testón.

27/11/2020 Seguro de Salud, organizado por Instituto de Derecho del Seguro del Colegio de abogados de Santa Fe (CASF), siendo disertante el miembro de nuestra asociación Dr. Dante Cracogna.

03/12/2020 Seguro y Nuevas Tecnologías, organizado por el Instituto de Derecho del Seguro del Colegio de Abogados de Entre Ríos. Disertante. Andrea Signorino Barbat.

14/12/2020 tema y orador a designar, será el cierre del año 2020.

Todas estas actividades virtuales pueden ser vistas nuevamente en el canal de YouTube de AIDA Joven Argentina https:/www.youtube.com/channel/UC7Xad982stqPJBI3Fg4uvOQ

\section{Brasil}

Aida Brasil, llevó a cabo las siguientes actividades

Nombre del evento: II Encuentro de seguro de responsabilidad civil (Reseña enviada por el Dr. Sergio Barroso de mello).

Fecha: 6, 13, 20 E 27 de octubre de 2020.

Organizado por: Grupo nacional de Trabalho de Responsabilidade Civil e Seguro Da Aida Brasil.

Desarrollo del programa

Primer Panel: Día 6/10/2020-17:00. 
Tema: Factores que influyen en la suscripción del Seguro de Responsabilidad Civil en Brasil y medidas concretas para el éxito empresarial.

Composición

Mediador: Dr. Sergio Ruy Barroso de Mello (Presidente del Grupo de Trabajo Nacional de Responsabilidad Civil y Seguros de AIDA Brasil).

Ponente 1: Dr. Márcio Guerrero (Presidente de la Comisión de Responsabilidad Civil de la Federación Nacional de Seguros Generales-FENSEG).

Ponente 2: Dr. Sergio Narciso (Presidente de la Comisión de Responsabilidad Civil de la Federación Nacional de Empresas Reaseguradoras-FENABER).

Tema 3: Dr. Christian Mendonça (Asociación Brasileña de Gestión de RiesgosABGR).

Debate: Dr. Robert Hufgel (Representante de la Cátedra de Responsabilidad Civil y Seguros de la Academia Nacional de Seguros y Bienestar Social-ANSP).

Segundo panel: 13/10/2020-17:00.

Tema: Medidas prudenciales en el ámbito del Seguro de Responsabilidad Profesional (E\&O), Administradores (D\&O) y Cyber Risks (CYBER): claridad contractual; transparencia en la relación comercial; medidas para reducir la judicialización; mejores prácticas en la regulación de quejas; etc. ...

Composición

Mediador: Dr. Sergio Ruy Barroso de Mello (Presidente del Grupo Nacional de Trabajo de Responsabilidad Civil y Seguros de AIDA Brasil).

Ponente 1: Dr. Flávio Sá (Presidente del Subcomité de Líneas Financieras de la Federación Nacional de Seguros Generales-FENSEG).

Ponente 2: Dr. Maurício Bandeira (Responsable de Riesgos Financieros de AON Brasil. Representante de la Comisión Técnica de RC de SINCOR-SP).

Ponente 3: Dra. Mariana Ferraz (Presidenta del Grupo de Trabajo de Líneas Financieras Nacionales de AIDA Brasil).

Debate: Dr. Felipe Barreto (Presidente de la Cátedra de Responsabilidad Civil y Seguros de la Academia Nacional de Seguros y Bienestar Social-ANSP).

Tercer panel: 20/10/2020-17:00.

Tema: Desafíos del Seguro de Responsabilidad Ambiental.

Composición

Mediador: Dr. Sergio Ruy Barroso de Mello (Presidente del Grupo de Trabajo Nacional de Responsabilidad Civil y Seguros de AIDA Brasil). 
Ponente 1: Dra. Nathalia Gallinari (Suscriptor de AIG Seguradora).

Ponente 2: Dr. Marco Ferreira (Socio Fundador de SUSTENSEG Seguros e Riscos Environmental).

Ponente 3: Dr. Pery Saraiva (Presidente del Grupo de Trabajo Nacional de Seguros Ambientales de AIDA Brasil).

Ponente 4: Profesora Dra. Gabrielle Tusa (Instituto Brasileño de Derecho Contractual-IBDCONT).

Cuarto Panel: Día 27/10/2020-17:00.

Tema: La experiencia internacional del Seguro de Responsabilidad.

Composición

Mediador: Dr. Sergio Ruy Barroso de Mello (Presidente del Grupo de Trabajo Nacional de Responsabilidad Civil y Seguros de AIDA Brasil)

Ponente 1: Profesora Dra. Andrea Signorino (Presidenta de AIDA Uruguay y Secretaria General de AIDA Mundial)

Ponente 2: Profesor Dr. Pedro País de Vasconcelos (Catedrático de la Universidad Clásica de Lisboa y Miembro del Consejo Presidencial de AIDA Mundial)

Ponente 3: Profesor Dr. Gabriel Vivas (Presidente del Grupo de Trabajo Internacional de Responsabilidad Global AIDA).

Ciclo de conferencia anterior al lanzamiento del Código de Procedimiento Civil anotado y comentado - Editora Rideel y Aida Brasil (reseña enviada por Luís Antônio Giampaulo Sarro)

Organizado por Luís Antônio Giampaulo Sarro.

Eventos quincenales.

16.07.2020: Código de Procedimiento Civil. Acierto, error y carácter fiscal mitigado de la apelación interlocutoria ponente: Fredie Didier Júnior.

31.07.2020: Apelaciones en Tribunales Superiores en tiempos de pandemia ponente: Paulo Henrique dos Santos Lucon.

14.08.2020: Propuesta para reorganizar la estructura de recursos a la luz de CPC / 2015. Ponente: Luiz Henrique Volpe Camargo.

14.08.2020: ¿Cómo hacer efectiva la audiencia de conciliación o mediación del artículo 334 del CPC? Ponente: Vivien Lys Porto Ferreira da Silva.

28.08.2020: Procedimientos civiles y de seguros.

Ponente Luís Antônio Giampaulo Sarro.

28.08.2020: Estabilización de la tutela anticipada.

Ponente: America Cardoso Barreto Lima Nejaim. 
11.09.2020: Principios del Código de Procedimiento Civil.

Ponente: Des. Alexandre Freitas Câmara.

11.09.2020: Queja ponente: Nathaly Campitelli Roque.

24.09.2020 Apuntes sobre aspectos controvertidos y actuales de los recursos civiles.

Ponente: José Miguel Garcia Medina.

24.09.2020: Fraude en ejecución ponente: Rita Dias Nolasco.

08.10.2020: Acciones familiares ponente: Lívia Dalla Bernardina Abreu.

08.10.2020 Adjunto del porcentaje sobre facturación (CPC, art. 866).

Ponente: Elias Marques de Medeiros Neto.

22.10.2020; Técnicas de estandarización de decisiones y proceso colectivo.

Ponente: Patrícia Miranda Pizzol.

22.10.2020: Condiciones de la acción en CPC / 2015.

Ponente: João Eberhardt Francisco.

05.11.2020: Amicus Curiae.

Ponente Rogéria Fagundes Dotti.

05.11.2020: Conflicto de competencia.

Ponene: Leonardo Carneiro da Cunha.

19.11.2020: Estabilidad de la decisión de reorganización.

Ponente: Carolina Uzeda Libardoni.

19.11.2020: Tutela Provisional en Apelaciones.

Ponente José Henrique Mouta Araújo.

03.12.2020: Posibles formas de mejorar la técnica de Tutela Provisional.

Ponente: Ester Camila Gomes Norato Rezende.

03.12.2020 título de la conferencia: Primacía de la sentencia en apelación.

Ponente: Maurício Ferreira Cunha.

17.12.2020 Primera producción de pruebas.

Ponente: Marcela Kohlbach de Faria.

17.12.2020: Acción de rescisión.

Ponente: Rafael Knorr Lippmann.

Los eventos incluyen conferencias de los coautores del Código Procesal Civil Anotado y comentados sobre diversos institutos procesales civiles. 
"El presente trabajo, que inició con las dos primeras ediciones del Nuevo Código Procesal Civil - Principales cambios en el sistema procesal civil, es parte del aporte de estos importantes grupos de trabajo, en este caso, por la Mesa Nacional de Procesos Civil, a la que acompañó, propuso una mejora al entonces Anteproyecto de Ley de Nuevo Código de Procedimiento Civil desde antes de la entrega del Anteproyecto de Ley por parte de la Comisión de Juristas, presidida por el Min. Luiz fux, al Senado Federal, que dio origen al PLS n ${ }^{\circ} 166$ / 2010. (...)".

Las dos primeras ediciones publicadas anteriormente no fueron trabajos comentados, sino meramente un comentario objetivo y objetivo sobre las novedades del Código Procesal Civil / 2015. Este trabajo, en cambio, avanza un poco más y trae comentarios sobre las principales disposiciones del Código de Procedimiento Civil 2015 de Maestros, médicos, jueces, fiscales, jueces, defensores públicos, miembros de la AGU, Hacienda Nacional, fiscales estatales y municipales y abogados, así como anotaciones de declaraciones interpretativas del Foro Permanente de Procesalistas Civiles (FPPC), la Escuela Nacional para la Formación y Perfeccionamiento de Magistrados (ENFAM) y el Consejo Federal de Justicia (CJF) - Jornadas del Derecho Procesal Civil.

Sin embargo, el trabajo sigue enriqueciéndose con varios artículos de reconocidos abogados, algunos de los cuales fueron miembros de las comisiones que redactaron el proyecto de ley (Humberto Theodoro Júnior y José Miguel García Medina) y que apoyaron a los relatores generales durante la tramitación del proyecto de ley. en el Senado Federal y la Cámara de Diputados (Luiz Henrique Volpe Camargo, Fredie Didier Júnior, Alexandre Freitas Câmara y Paulo Henrique dos Santos Lucon), entre otros juristas fuertes (Rodolfo de Camargo Mancuso, Nathaly Campitelli Roque, Ernesto Antunes de Carvalho, Rafael de Oliveira Guimarães, Rennan Faria Krüger Thamay, Eduardo Talamini, Antônio Carlos Marcato)". (Código Procesal Civil Anotado Comentó. Coordinación de Luís Antônio Giampaulo Sarro, Luiz Henrique Volpe Camargo y Paulo Henrique dos Santos Lucon. São Paulo: Ed. Rideel, 2020, pág. XXXVIII y XXXIX).

Agradecimientos especiales. AIDA BRASIL agradece a todos los coordinadores y coautores por donar el Derecho a Regalías por las actividades académicas de sus grupos de trabajo nacionales y regionales.

La AIDA BRASIL agradece a todos los coordinadores y coautores por donar el Derecho a Regalías por las actividades académicas de sus grupos de trabajo nacionales $\mathrm{y}$ regionales.

Seminario AIDA: covidas y retos del derecho de seguros.

Reseña enviada Ana Paula Bonilha de Toledo.

Grupo Nacional de Trabajo de Relaciones con el Consumidor de la Asociación Nacional de Derecho de Seguros (AIDA Brasil).

Lugar: Se realiza en línea, se transmite en el Canal de YouTube de AIDA Brasil (enlace: https://www.youtube.com/watch?v=XVXYGclwBG0) y en la página de Facebook de AIDA Brasil.

30 de abril de 2020 . 
Desarrollo del programa: El seminario fue mediado por Pery Saraiva Neto y los polemistas Ana Paula Costa (Presidenta de Relaciones con el Consumidor GNT de AIDA Brasil), André Tavares (Presidente de Garantía GNT de AIDA Brasil) y Nathália Menezes (Vicepresidente de Relaciones con el Consumidor GNT de AIDA Brasil), quien realizó presentaciones sobre el tema y respondió preguntas enviadas por los espectadores.

COVID y los retos actuales en la ejecución de contratos.

Ponente Pery Saraiva Neto (Director Académico de AIDA). Brasil.

El Grupo Nacional de Trabajo de Relaciones con el Consumidor de la Asociación Nacional de Derecho de Seguros (AIDA Brasil) actúa desde 2012 en el análisis, propuesta de modificaciones y publicación de artículos sobre los distintos proyectos de Ley, en especial los núm. 281, 282 y 283 del Senado Federal, que proponen la "modernización" del Código de Protección al Consumidor. En esta línea, el Grupo busca resaltar aquellas reglas que puedan impactar en el mercado asegurador, proponiendo el debate y las soluciones legales. Actualmente está presidido por Ana Paula Costa.

Con la pandemia han surgido varios desafíos en la ejecución de contratos. Mucho se ha llegado a discutir sobre la exclusión que existe en la mayoría de los seguros para la cobertura de siniestros derivados de una pandemia, que es legítima y surge de un riesgo catastrófico, lo que dificulta la medición, e incluso puede llevar a la quiebra de la aseguradora.

Algunas aseguradoras han optado por pagar por eventos no cubiertos por el seguro, debido a la situación de la pandemia, por mero acto de caridad y solidaridad. Por supuesto, estos actos siempre son bienvenidos, sobre todo para superar momentos de crisis. Sin embargo, los pagos que realizan las compañías de seguros deben hacerse con el capital social de la empresa o el capital de los propios accionistas, y no con recursos de reservas técnicas, lo que termina creando un peligroso precedente, especialmente en Brasil, donde hay una tendencia a ignorar contratos, incluida la obligación de que el Poder Judicial lo haga.

Finalmente, también parece que se están interponiendo muchos juicios con el objetivo de suspender los efectos de los atrasos financieros y prohibir a la aseguradora denegar coberturas. Si el Poder Judicial da la garantía por el incumplimiento en estos contratos, el equilibrio actuarial de las aseguradoras y operadores de salud se verá afectado y los beneficiarios morosos se verán perjudicados, lo que puede incluso servir para estimular el incumplimiento. La ineficiencia del SUS y del Estado no se puede trasladar al sector privado, especialmente a la salud complementaria, imprescindible en el momento de la pandemia, para trabajar junto al sistema público de salud.

\section{Seminario online: ¿COVID-19 e a previdência privada - poupar ou sobreviver?}

Reseña enviada por Ivy Cassa.

Grupo de Trabajo Nacional de Relaciones con el Consumidor de la Asociación Nacional de Derecho de Seguros (AIDA Brasil). 
Lugar: Realizado en línea, transmitido en el canal de Youtube de AIDA Brasil (enlace: https://www.youtube.com/watch?v=YYDCtQx2dYY\&feature=youtu.be, y también en la página de Facebook de AIDA Brasil.

30 de abril de 2020.

El seminario fue mediado por Paulo Alexandre y Victor Benes y los polemistas Ivy Cassa (Presidenta del Fondo Privado de Pensiones de AIDA Brasil) y Jaqueline Suryan (Vicepresidenta del mismo grupo).

Seminario online: COVID-19 y pensión privada-¿Ahorrar o sobrevivir?

Ponente: Ivy Cassa (Presidenta del Fondo Privado de Pensiones de AIDA Brasil) y Jaqueline Suryan (Vicepresidenta del mismo grupo). Brasil.

Ivy Cassa tiene una licenciatura y una maestría en derecho de la Universidad de São Paulo, un MBA en seguros de la Fundación Getúlio Vargas y una especialización en seguros de vida, pensiones y salud de la Universidad de Salamanca. Jaqueline Suryan tiene una licenciatura y una maestría en derecho de la Universidad Pontificia de São Paulo (PUC-SP) y un MBA en Administración de Empresas y Pensiones de la Fundação Instituto de Administração (FIA).

- También tuvieron las próximas actividades

- Responsabilidad por la falta de camas de UCI y respiradores artificiales COVID-19.

- Vista práctica del escenario actual del seguro de automóvil entre pandemia.

- $\quad$ Cobertura de la pérdida de beneficios desde la perspectiva COVID-19.

- Garantía judicial de seguros: aspectos actuales en tiempos de COVID-19.

- Pandemia, derechos legales y su impacto en el contrato de seguro.

- Los impactos del COVID-19 en la logística y el seguro del transporte de carga.

Toda estas actividades virtuales pueden ser consultadas en el canal de YouTube de AIDA BRASIL https://www.youtube.com/channel/UCVhsQxDhEXoKDT7CRi7fmuQ.

\section{Bolivia}

El Evento denominado "AIDA BOLIVIA te invita: conversatorio 5.5.5” se realizó el 5 de agosto 2020 con la participación de los siguientes conferencistas.

Dr. Juan Manuel Diaz Granados/ Colombia-Efectos Relevantes en el Seguro de Responsabilidad Civil en relación al COVID-19.

Dra. Carmenza Mejia / Colombia. Afectación del COVID-19 y la Cuarentena en las Pólizas de Caución. 
Dr. Marcelo Barreto / Brasil-Efectos del COVID 19 en los Seguros de Automotores: reducción de primas y siniestros.

Dr. Luis Sandoval / Chile-Litigiosidad en Seguros por efecto del COVID-19.

Dr. Neftali Garro / Costa Rica-Efectos que tendrá la Pandemia en la Distribución de Seguros.

\section{El arbitraje mandatorio en seguros, la experiencia boliviana}

AIDA BOLIVIA, organizó el evento virtual bajo la modalidad de conversatorio.

Con el siguiente programa:

Dr. Jaime Ponce Garcia Palabras de apertura e introducción.

Participantes, abogados reconocidos, Arbitros y miembros de AIDA BOLIVIA.

Igor Vucsanovich.

Abogado, con 20 años de experiencia en el ámbito de la solución alternativa de disputas, magister en Derecho Económico Internacional de la Universidad Externado de Colombia y especialidades en otras universidades.

Profesor de Métodos Alternos de Solución de Disputas en distintas universidades y eventos especializados, y miembro del cuerpo arbitral de la Cámara Nacional de Comercio, de la Cámara de Comercio de Cochabamba y de la Cámara de Industria y Comercio de Tarija, delegado del sector privado para el tratamiento de la actual ley de conciliación y arbitraje boliviana.

Actualmente es Gerente del centro de conciliación y arbitraje de la cámara nacional de comercio.

Maria Sandra Ramirez Bernal.

Abogada con especialidad en seguros de la universidad de salamanca., presidente del CILA 2018-2022 miembro del consejo mundial de presidencia de la Asociación Internacional De Derecho De Seguros AIDA (Asociacion international de droit de assurance) árbitro de la Cámara Nacional de Comercio.

Ivan Salame.

Miembro de AIDA BOLIVIA.

Árbitro. - Abogado-Maestría en Derecho Económico y Especialidad en Derecho Empresarial,--Profesor universitario-Autor de los libros: El proceso de Descentralización en Bolivia; Derecho Bancario-Coautor de: Justicia Constitucional en Bolivia.

Ronald Martin.

Especialista en derecho comercial, contratación y asesoramiento corporativo nacional e internacional, con más de 20 años de experiencia asesorando a empresas locales, multinacionales, organizaciones sin fines de lucro, embajadas, entidades estales entre otros. 
Es uno de los abogados más reconocidos en Bolivia y en la región en temas de arbitraje, habiendo actuado como abogado, árbitro o perito en arbitrajes de distinta envergadura y ante los principales centros nacionales e internacionales que operan en la región.

Arbitro de la Cámara Nacional de comercio.

Cayo Salinas.

Máster en "Derecho Empresarial - La Más Alta Distinción” por la Universidad Privada Boliviana con el apoyo académico de la Pontificia Universidad Javeriana de Bogotá-Colombia.

Graduado en los Estados Unidos de Norteamérica por la Corte Suprema del Estado de la Florida al haber cumplido con todos los requisitos exigidos en el programa de especialización de Nova Southeastern University Florida - USA como Mediador y Árbitro.

Es Árbitro con especialización en Comercio Internacional del Tribunal Internacional de Conciliación y Arbitraje del MERCOSUR/ALCA.

Arbitro de la Cámara nacional de comercio, del centro de la CNC de Cochabamba y CAINCO Socio principal de "Cayo Salinas \& Asociados - Estudio de abogados".

El evento fue moderado por Héctor Ponce de León miembro del directorio de AIDA BOLIVIA y Secretario general del CILA.

\section{Costa Rica}

\section{ACODES - Asociación Costarricense de Derecho de Seguros y las Fianzas.}

Seguro de desempleo - Fundamento legal y aspectos prácticos - 3 de septiembre.

Importancia del seguro de responsabilidad Civil de d\&o - 6 de agosto.

https://www.facebook.com/watch/?v=244241149884336\&extid=c04eFdm9nbLX3NNb

El Derecho de consumo como Derecho Humano - 20 de agosto.

https:/www.facebook.com/AIDACostaRica/videos/796449287561461/

La Asociación Costarricense de Derecho de Seguros y las Fianzas (ACODES), Capítulo AIDA-Costa Rica, ha realizado en los meses de agosto y setiembre una serie de conferencias sobre temas de Derecho de Seguros, que usted los puede localizar en la página de Facebook de esa Asociación : https://www.facebook.com/AIDACostaRica/ Este webinar corresponde a la ponencia realizada por el Lic. Boris Molina Acevedo bajo el título Derecho de consumo como Derecho Humano: obligado análisis de legalidad, de constitucionalidad y de convencionalidad, el día 20 de agosto del 2020. Boris 
Molina Acevedo El abogado Boris Molina Acevedo nace en San José, capital de la República de Costa Rica, un 21 de marzo de 1967. Boris es abogado litigante, consultor, conferencista, asesor jurídico, árbitro de Derecho y Profesor universitario. Es graduado de la Universidad de Costa Rica, donde obtiene Honores de Distinción máxima en su Tesis de Grado: "El consumidor de seguros en Costa Rica: Marco jurídico que regula su relación contractual." La versatilidad de Boris en las diferentes áreas del Derecho está marcada por su experiencia práctica en casos de diversos matices, amén de su experiencia de dos décadas como Agente Asesor y perito en Seguros. Es el fundador y socio Presidente de la Firma B Molina Abogados (https:// www.borismolinaabogados.com/es/) Es el actual Vicepresidente de la Asociación Costarricense de Derecho de Seguros y las Fianzas (ACODES), Sección AIDA (Association Internationale du Droit des Assurances), Costa Rica. Boris funge como Director General de la Federación Nacional de Asociaciones de Consumidores y Usuarios de Costa Rica (FENASCO). Dentro del panel de neutrales, en su condición de árbitro de Derecho, Boris forma parte del Centro Internacional de Conciliación y Arbitraje (CICA) (http://cica.co.cr/pages/neutrales). Entre el 2013 y el 2018, Boris fungió como Juez-Árbitro de la Cámara Nacional de Resolución de Disputas de la Federación Nacional de Fútbol de Costa Rica (FEDEFUT) (https://www.fedefutbol. com/wp-content). En su experiencia como litigante, Boris es internacionalmente conocido por haber sido el abogado que representó al 70\% de las víctimas en el caso más emblemático de la Historia de la Corte Interamericana de Derechos Humanos, a saber, el Caso Artavia Murillo y otros vs Costa Rica (Fecundación in vitro): http:// www.corteidh.or.cr/cf/Jurispru. Caso que le permitió el más alto reconocimiento de la "Inter-American Bar Association/Lexis Nexis Latin America Rule of Law Award 2019", "Premio Estado de Derecho 2019, de la Federación Interamericana de Abogados (FIA)", San José, Costa Rica, el 19 de junio del 2019, otorgado por esta organización internacional de abogados, entregado en el marco de la 55a Conferencia Anual de la FIA. Premio que por vez primera lo recibe un costarricense. Este premio lo otorga la Inter American Bar Association (Federación Interamericana de Abogados) en conjunto con Lexis-Nexis y se concede a personas que hayan demostrado una muy destacada labor en la defensa del Estado de Derecho en el continente americano. En este caso, un significativo aporte a los Derechos Humanos.

https://www.youtube.com/watch?v=3AtbctSvv6c

\section{Jornadas de derecho de seguros}

Lunes 23 de noviembre.

Sesión 1: Conferencia Inaugural-Nuevas Tecnologías, Big Data \& Smart Contracts en Seguros.

- Neftalí Garro, Costa Rica, Presidente de la Junta Directiva, ACODES.

- Álvaro Hernández, Costa Rica, Presidente, Comisión de Derecho Civil \& Mercantil, Colegio de Abogados \& Abogadas de Costa Rica. 
Sesión 2: Conferencia-Contratos, Neurociencias e Inteligencia Artificial en Seguros.

- Prof. Waldo Sobrino, Argentina.

- Moderador: Boris Molina Acevedo, Costa Rica, Vicepresidente de la Junta Directiva.

Sesión 3: Conferencia-Ciencias Forenses y Seguros:

Una Alianza Estratégica.

- Boris Molina Mathiew, Costa Rica.

- Moderador: Esteban Carranza, Costa Rica, Tesorero de la Junta Directiva, ACODES.

- $\quad$ Prof. Abel Veiga Copo, España.

- Moderador: Neftalí Garro, Costa Rica, Presidente de la Junta Directiva, ACODES.

Sesión 4: Mesa Redonda - Innovación y Transformación.

Digitales en Seguros.

- Javier Solís, Costa Rica, "Los Retos de las Compañías de Seguros Frente a la Transformación Digital".

- Silvia Canales, Costa Rica, "Hacia una Estrategia Digital en Seguros. Consideraciones sobre Gobernanza y Gestión de Riesgos por parte de los Sujetos Regulados".

- Miguel Ángel de la Fuente, México, "Una Visión Legal al Impacto de la Analítica de Datos (Data Analytics) en el Sector Asegurador".

- Moderador: Carlos García, Vocal de la Junta Directiva, ACODES.

Sesión 5: Conferencia - El Derecho de Seguros Frente a la Responsabilidad Penal de las Personas Jurídicas: Un Enfoque de Derecho Comparado (Inscríbase aquí).

- Boris Molina Acevedo, Costa Rica.

- Moderador: Jaime Garro, Vocal de la Junta Directiva, ACODES.

Miércoles 25 de noviembre.

Sesión 6: Mesa Redonda: Disrupción, Innovación Digital y su Impacto en la Industria de Seguros.

- Prof. Joseba G. Angulo, España.

- $\quad$ Nancy Arias, Costa Rica.

- Moderador: Luis Guillén, Costa Rica, Asociado ACODES. 
Sesión 7: Conferencia - Contratos de Reaseguro.

Legislación Aplicable e Interpretación de Cláusulas Contractuales bajo Ley Inglesa.

- Rebeca Herrera, Colombia, Presidenta del Grupo de Trabajo de Reaseguro del CILA.

- Moderador: Alexis Arias, Fiscal ACODES.

Sesión 8: Conferencia - Los Seguros de Personas: Disposiciones Esenciales en las Leyes de Seguros de Uruguay y Costa Rica.

- Dra. Andrea Signorino, Uruguay, Miembro Consejo de Presidencia y Comité Ejecutivo de AIDA, Ex Presidenta del CILA.

- Moderador: Alexis Arias, Costa Rica, Fiscal de ACODES.

Sesión 9: Conferencia - Perspectiva Crítica sobre Disputas Contractuales: Múltiples Opciones, Pocas Soluciones.

- Esteban Carranza, Costa Rica.

- Moderador: William Fernández, Vocal de la Junta Directiva, ACODES.

Jueves 26 de noviembre.

Sesión 10: Conferencia - Los Seguros Autoexpedibles como Mecanismo de Inclusión Financiera: Perspectivas y Normativa Vigente.

- $\quad$ Ever Olivares, Costa Rica.

- Moderadora: Lorena Murillo, Costa Rica. Secretaria de la Junta Directiva, ACODES.

Viernes 27 de noviembre.

Sesión 11: Mesa Redonda - Seguros de Responsabilidad Civil: Temas de Actualidad y Aspectos Prácticos.

- Sandra Ramírez, Bolivia, Presidente del CILA.

- Marvin Umaña, Costa Rica, Socio, ASPROSE Corredores de Seguros, S.A.

- Gabriel Vivas, Colombia, Presidente del Grupo de Trabajo de Seguros.

Responsabilidad Civil de AIDA y CILA.

- Moderador: Boris Molina Acevedo, Costa Rica, Vicepresidente de la Junta Directiva de ACODES.

Cierre de las V Jornadas.

- Sandra Ramírez, Bolivia, Presidente del CILA.

- Neftalí Garro, Costa Rica, Presidente de la Junta Directiva, ACODES. 


\section{Colombia}

Introducción al Seguro Marítimo

https://www.youtube.com/watch?v=GafTUZfB-fo

El impacto del COVID-19 en seguros: seguro de salud y seguro de arrendamiento https://www.youtube.com/watch?v=yT8Fv_NSM7I

El nuevo esquema procesal: impacto del decreto legislativo 806 DE 2020.

https://www.youtube.com/watch?v=EVIqMi-T97k

Presentación del Decreto 806 y de las estrategias que desde el gobierno nacional. https://www.youtube.com/watch?v=jPihXhAEIkY

\section{México}

\section{AMEDESEF.}

¿Requerimos contar con una nueva Ley sobre el Contrato de Seguro en México? La Asociación Mexicana de Derecho de Seguros y Fianzas, A.C. (Amedesef) organiza un ciclo de mesas redondas virtuales en las que se hablará del tema.

Clausulas claime made y prescripción - 21 de agosto.

https:/www.youtube.com/watch?v=dpTmN6mIdLs

Causales de terminación de los contratos de seguro - 13 de agosto.

https://www.youtube.com/watch?v=bzGwzoaDUvA

Siniestros y reclamaciones - 06 de agosto.

https://www.youtube.com/watch?v=5b2BwMS3pR0

Modificación esencial del riesgo e implicaciones en la prima - 30 de julio.

https://www.youtube.com/watch?v=LRPT2q0TvUo

Obligaciones del contratante y asegurado - 23 de julio.

https://www.youtube.com/watch?v=IXiMhyWEg5Y

Nueva perspectiva para entender el contrato de seguro - 10 de junio.

https://www.youtube.com/watch?v=YHE8wOaFyM0

\section{Otras organizaciones}

LA AIDDP, Asociación Ibero latinoamericana de Derecho privado llevó a cabo un curso internacional de Responsabilidad civil en coordinación con la U de Colombia Corporación Universitaria - U de Champagnat de Argentina e IJ Editores con el siguiente programa. 


\section{Programa}

Julio 14/202: Funciones de la responsabilidad civil. Francisco Segura (Paraguay). Profesor de la U. Americana del Paraguay, director de la Colección de Manuales de Derecho Privado Paraguayo y de la Revista Paraguaya de Responsabilidad Civil y Seguros, director del Capítulo Paraguayo de la Asociación Iberoamericana de Derecho Privado (AIDDP), magíster en Derecho por la U. Nacional de Rosario (Argentina).

Julio 16/2020: Elementos de la responsabilidad civil. Juan Marcos Rivero (Costa Rica). Catedrático de la U. de Costa Rica, director de la Revista de la Cátedra Centroamericana de Derecho Romano, vicepresidente del Capítulo Costarricense del Instituto Iberoamericano de Derecho Procesal, doctor en Derecho por la Johann Wolfgang Göthe Universität, Frankfurt (Alemania), miembro de la Asociación Henri Capitant.

Julio 21/2020: Responsabilidad civil contractual y extracontractual. Federico Ossola (Argentina). Vocal de la Cámara Cuarta de Apelaciones en lo Civil y Comercial de Córdoba (Argentina), profesor de la U. Nacional de Córdoba, doctor en Derecho y Ciencias Sociales por la U. Nacional de Córdoba.

Julio 23/2020: La culpa como factor de atribución. Responsabilidad subjetiva. Andrés Mariño (Uruguay). Catedrático y coordinador académico de la maestría en Derecho de Daños de la U. de la República Oriental del Uruguay, doctor en Derecho Suma Cum Laude por la U. Autónoma de Barcelona (España), director de la Revista Crítica de Derecho Privado.

Julio 28/2020: Responsabilidad objetiva. Teoría del riesgo. Daniel Pizarro (Argentina). Profesor titular de la U. Nacional de Córdoba (Argentina), miembro de número de la Academia Nacional de Derecho y Ciencias Sociales de Córdoba, doctor en Derecho y Ciencias Sociales por la U. Nacional de Córdoba, Premio Konex 2016, autor de "Tratado de la responsabilidad objetiva" y "Responsabilidad por el riesgo o vicio de la cosa".

Julio 30/2020: Eximentes de la responsabilidad. José Antonio Badillo (España). Delegado Territorial de Madrid del Consorcio de Compensación de Seguros, director de la revista Responsabilidad Civil, Circulación y Seguro, profesor de la U. de Alcalá, doctor en Derecho por la U. Carlos III de Madrid.

Agosto 4/2020: Teoría general del daño. Pascual Alferillo (Argentina). Exjuez de Cámara en lo Civil, Comercial y Minería de San Juan (Argentina), miembro de la Academia Nacional de Derecho y Ciencias Sociales de Córdoba (Argentina), doctor en Ciencias Jurídicas por la U. de Mendoza, secretario general de la Asociación Iberoamericana de Derecho Privado (AIDDP).

Agosto 6/2020: La reparación integral del daño. Carmen Domínguez Hidalgo (Chile). Profesora titular de la Pontificia Universidad Católica de Chile, presidenta de la Red Internacional de Institutos de Familia (REDIUF), doctora en Derecho por la U. Complutense de Madrid, exconjuez de la Corte de Apelaciones de Santiago, consejera del Colegio de Abogados de Chile y de la Academia Judicial de Chile, directora del Ca- 
pítulo Chileno de la Asociación Iberoamericana de Derecho Privado (AIDDP), autora de "El principio de reparación integral en sus contornos actuales".

Agosto 11/2020: La pérdida de la chance como daño resarcible. Gustavo Ordoqui (Uruguay). Profesor de la U. de Montevideo y la U. Católica de Uruguay, miembro de las Academias de Derecho y Ciencias Sociales de Córdoba, Iusprivatista de Pavia y Provida del Vaticano, miembro de la Comisión de Honor de la Asociación Iberoamericana de Derecho Privado (AIDDP) y autor del "Tratado de Derecho de los Contratos" (9 tomos).

Agosto 13/2020: Daños punitivos. Manuel Cornet (Argentina). Profesor de la U. Nacional de Córdoba y la U. Católica de Córdoba (Argentina), director del Instituto de Derecho Civil de la U. Católica de Córdoba, vicepresidente de la Asociación Iberoamericana de Derecho Privado (AIDDP).

Agosto 18/2020: Daños colectivos. Lidia Garrido Cordobera (Argentina). Profesora titular de la U. de Buenos Aires, académica correspondiente de la Academia Nacional de Derecho y Ciencias Sociales de Córdoba, doctora en Derecho por la U. de Buenos Aires, secretaria académica de la Asociación Iberoamericana de Derecho Privado (AIDDP).

Agosto 20/2020: Valoración y cuantificación del daño. Alfredo Ferrante (Chile). Director del Departamento de Derecho Privado de la U. Alberto Hurtado (Chile), doctor en Derecho por la U. de Oviedo (España), coordinador de la sección de «Obligaciones y contratos» del Instituto de Derecho Iberoamericano (IDIBE).

Agosto 25/2020: La mora en la responsabilidad civil contractual. Mario Castillo Freyre (Perú). Profesor titular de la Pontificia Universidad Católica del Perú (PUCP), miembro de número de la Academia Peruana de Derecho, doctor en Derecho por la PUCP, ex decano de la Universidad Católica San Pablo de Arequipa, vicepresidente de la Asociación Iberoamericana de Derecho Privado (AIDDP).

\section{Curso Iberoamericano de Responsabilidad Civil}

\section{Parte especial}

Asociación Iberoamericana de Derecho Privado (AIDDP) - U de Colombia Corporación Universitaria - U de Champagnat de Argentina - IJ Editores.

Programa

Septiembre 8/2020: Responsabilidad por el hecho de un tercero. Julián Jalil (Argentina). Juez de la Cámara de Apelaciones de Puerto Madryn (Argentina), doctor en Derecho por la UCES (Argentina), posgraduado en la U. de París, Bologna y Salamanca, autor del "Tratado de la Responsabilidad Civil".

Septiembre 10/2020: Responsabilidad civil en los accidentes de circulación. Sandra Ramírez (Bolivia). Presidenta del Comité Ibero Latinoamericano (CILA) de Asocia- 
ción Internacional de Derecho de Seguros (AIDA), árbitra de la Cámara Nacional de Comercio de Bolivia y del Centro de Arbitraje Internacional Arias Latam, directora del Capítulo Boliviano de la Asociación Iberoamericana de Derecho Privado (AIDDP).

Septiembre 15/2020: Responsabilidad civil en el transporte. Federico Torrealba (Costa Rica). Profesor de la U. de Costa Rica, miembro del Consejo Directivo de la Asociación Iberoamericana de Derecho Privado, autor de "Responsabilidad Civil" y "Principios del Derecho Privado".

Septiembre 17/2020: Responsabilidad civil en la construcción. Diana Barrientos Gómez (Colombia). Máster en Educación y Desarrollo Humano Cinde- U. de Manizales (Colombia), especialista en responsabilidad civil y seguros U. Eafit y derecho comercial U. Pontificia Bolivariana, miembro fundador del Instituto Colombiano de Responsabilidad Civil y del Estado, docente en el Marco legal de la construcción U. Eafit, consultora y litigante en derecho de la construcción e inmobiliario.

Septiembre 22/2020: Responsabilidad civil médica. Alberto Duque OSORIO (Colombia). Médico y abogado, especialista en Gerencia Hospitalaria Universidades CES - EAFIT (Colombia), y responsabilidad civil y seguros U. EAFIT, magister en Derecho por la U. de Antioquia, profesor en derecho médico, autor del "Tema de prueba en la responsabilidad médica".

Septiembre 24/2020: Responsabilidad civil en las relaciones de consumo. Sebastián Barocelli (Argentina). Profesor de la U. de Buenos Aires y la U del Salvador (Argentina), miembro de la mesa directiva de la Asociación Internacional de Derecho del Consumidor (IACL), secretario académico del Instituto Argentino de Derecho del Consumidor (IADC), codirector de la Revista Argentina de Derecho del Consumidor.

Septiembre 29/2020: Responsabilidad civil profesional. Miguel Ángel de la Fuente (México). Presidente de la Asociación Mexicana de Derecho de Seguros y Fianzas, A.C., profesor de la U. Anáhuac (México), máster en Derecho Financiero Internacional por el King College of London, asociado principal de Garrigues México.

Octubre 1/2020: Responsabilidad civil en la educación. Gustavo Vallespinos (Argentina). Profesor titular de la U. Nacional de Córdoba (Argentina), miembro de número de la Academia Nacional de Derecho y Ciencias Sociales de Córdoba, doctor en Derecho y Ciencias Sociales por la U. Nacional de Córdoba, director académico de la Sala Civil del Colegio de Abogados de Córdoba y de la Asociación de Magistrados de la Provincia de Córdoba.

Octubre 6/2020: Responsabilidad civil en las relaciones de familia. Ana Paula Giménez (Brasil). Directora de la Revista Especializada de Derecho Civil IJ en Brasil, directora del Capítulo Brasileño de la Asociación Iberoamericana de Derecho Privado (AIDDP), doctoranda en Derecho Civil de la U. de Buenos Aires.

Octubre 8/2020: Responsabilidad ambiental. Francisco Játiva (Ecuador). Profesor titular de la U. de las Américas y la U. Central del Ecuador, exdirector nacional de Registro y Regulación Legal Minera del Ecuador, máster en Derecho Privado Internacional. 
Octubre 13/2020: Responsabilidad civil en la informática y redes sociales. Walter Krieger (Argentina). Profesor de la U. de Buenos Aires, la U. Católica Argentina y la U. del CEMA, doctor en Derecho por la UCES (Argentina), director del Capítulo Argentino de la Asociación Iberoamericana de Derecho Privado (AIDDP).

Octubre 15/2020: Responsabilidad de la administración pública. Pilar Domínguez (España). Profesora titular de la U. de Castilla La Mancha-UCLM- (España), doctora en Derecho Suma Cum Laude por la UCLM, Premio Nacional Jurídico "Santiago Gutiérrez Anaya" X edición, autora de la "Responsabilidad Patrimonial de la Administración por accidentes tráfico".

OCTUBRE 20/2020: Seguro de responsabilidad civil. Carlos Humberto Montoya Ortega (Colombia). Presidente de la Asociación Iberoamericana de Derecho Privado, Árbitro de la Cámara de Comercio de Medellín y de La Lonja de Propiedad Raíz de Medellín, especialista en responsabilidad civil y seguros.

Todos los videos pueden ser vistos en la plataforma de WOLAP, IJ Editores.

Instituto de Derecho de seguros de Paraguay

En forma conjunta con la Universidad Católica Nuestra Señora de la Asunción, lleva a cabo el Primer Diplomado sobre Derecho de Seguros, se inició en el mes de setiembre y concluye el 17 de diciembre del cte. año.

El mismo conto con la participación de expositores extranjeros, siendo dichas exposiciones abiertas a todo público.

Estuvieron entre otros, el Dr. Abel Veiga Copo, Andrea Signorino, Francisco Artigas, Martin Argarañaz, María Fabiana Compiani.

Los temas expuestos fueron: Elementos Esenciales del Contrato de Seguros; El Seguro de Responsabilidad Civil, Reaseguro, El Seguro de Caución y la Suspensión automática de la cobertura por falta de pago de la prima.

Los docentes paraguayos, son: Bibiana Gill, Stael Cabral, Zunilda Benavente, Juan Francisco Pérez, Guillermo Fronciani, José Luis Vega y Miguel Ángel Berni.

Igualmente, el Instituto de Derecho de Seguros, en forma conjunta con la Asociación Paraguaya de Compañías de Seguros, realizo en el mes de noviembre pasado, charlas virtuales, tocando temas como el Seguro de Responsabilidad Civil y El Seguro Obligatorio para Automotores, considerando que nuevamente se encuentra un anteproyecto de Ley en el Congreso Nacional, habiendo sido derogada la anterior Ley del SOAT, poco después de su promulgación en el año 2014.

\section{COPADES}

Desde el año 2015 COPADES responde a necesidad imperante del sector asegurador y de intermediación, en procurar los espacios de formación, fortalecimiento y de la actualización, de las mejores prácticas Internacionales en temas de sensible importancia para el mercado y la sociedad. 


\section{Programa}

Domingo 13 (apertura e inauguración 06:00 - 08:00 PM).

06:00 pm Apertura Formal - Palabras de Apertura.

06:30 pm Panel de Apertura sobre Fraudes en las Reclamaciones de Seguros. Perspectivas y Experiencias en Brasil. - Moderador: Lic. Edwin Granados, EPLC Criminólogo - Costa Rica.

Panelista: Dr. Leonardo Mendonça - Brasil (Abogado Criminalista, Profesor en la Escuela.

Nacional de Seguros. Socio propietario de Leonardo Mendoza Abogados.

Panelista: Dr. Ricardo Tavares - Brasil (Gerente de la Confederación Nacional de Seguros.

Gerente de Prevención y Combate del Fraude en Seguros).

Panelista: Dr. Abelardo Guimarães - Brasil (Vicepresidente de la Comisión de Fraudes y Superintendente de Bradesco Seguros).

07:30 pm Acto de Inauguración Formal.

Lunes 14 - Sección matutina (08:30 am - 01:00 pm).

08:30 am Conversatorio sobre la Tipología del Delito del Fraude a los Seguros, en el Contexto LATAM, Derecho Comparado.

Dra. Andrea Signorino Barbat - Secretaria General de AIDA Mundial, Asesora Legal y Técnica en Seguros y Reaseguros de Uruguay.

Dra. Nora Claros - Secretaria del Grupo de Fraude al Seguro del CILA (Comité Ibero-latiamericano de AIDA) Gerente Nacional Corporativa Legal de Alianza - Bolivia.

Dra. Marielos Hernández - Socia Fundadora de CLAIMS International - El Salvador.

09:15 am Simposio: Control de Riesgo de Fraudes y Lavado de Activos y Financiación del Terrorismo.

Lic. Lillian G. Báez Ureña. Encargada del Departamento de Prevención de Lavado de Activos de la Dirección General de Impuestos Internos - Republica Dominicana.

- $\quad$ En Aseguradoras - Lic. Hugo Jiménez, CFE, Consultor Antifraude y en Gestión de Riesgos, CEO de Risk Control Consulting. - México.

- En Inmobiliarias - Lic. Heiromy Castro - Asesor en Prevención de Lavado de Activos, Director General de Cumplimiento de Banreservas - República Dominicana.

- En Sector Financiero - Lic. Ramón Nicolás Jiménez, Especialista en Prevención de Lavado de Activos, Director del Programa Retos y Desafíos - República Dominicana. 
10:45 am Intermedio - Espacio Comercial.

11:15 am Logrando las Metas Comerciales al Menor Riesgo y Costo Organizacional.

Lic. Iván E. Galvis Castañeda, Psicólogo Forense, Especialista en Psicología Jurídica, Master en Inteligencia Estratégica, Master en Seguridad y Defensa Nacional - Colombia.

12:30 pm Sección de Preguntas y Respuestas (Dr. Enrique Cambier - República Dominicana.

Martes 15 - Sección (solo MATURINA de 08:30 AM - 12:30 PM).

08:30 am Seguridad Tecnológica ante Ciberdelitos Post Pandemia.

Ing. Oscar Rosa, Detective Investigador Privado, Experto en Fraude y Compliance.

Director General de Detectys en Madrid - España.

09:30 am Uso de Inteligencia Artificial en Detección de Fraudes y Evaluación de Riesgos.

Ing. Oscar Moratto, Especialista Financiero en Mitigación de AML/ATF e Inteligencia.

Financiera, Consultor Anti lavado asociado a RICS Management - Colombia.

10:30 am Deberes y Responsabilidades del Directorio de la Empresa de Seguros en el Combate al Fraude y la Corrupción.

Dr. Guillermo Bolado, Abogado. Ex Vicesuperintendente de Seguros de la Nación Argentina. Director Independiente de SMSV Compañía de Seguros. Titular de "Bolado \& Asociados, Abogados". - Argentina.

11:30 pm El Perfil del Oficial de Cumplimiento. Diferencias en las Obligaciones entre el Sector Financiero y el Sector Asegurador.

12:30 pm Sección de Preguntas y Respuestas (Lic. Dicla Emperatriz López - República Dominicana.

Miércoles 16 - sección (vespertina DE 02:30 - 06:30 PM).

02:30 pm Los Hechos de Tránsito, como Herramienta en el Proceso de Investigación Forense para el Establecimiento de Siniestros Fraudulentos.

Lic. Tomás González Guerrero, Investigador Forense, Perito Auxiliar de la Administración de Justicia, Miembro del Consejo de la Judicatura de Jalisco - México.

03:15 pm Avances Tecnológicos en Nuevos Productos de Seguros de Automóviles y sus Beneficios comerciales y Como Control de Riesgo de Fraudes. Modelo Brasileño: Pay as You Drive.

Lic. Marcelo Baccarini, Especialista en Prevención de Fraude (SIU) en YOUSE Caixa - Brasil.

04:30 pm Como Puede el Intermediario de Seguros Generar Suscripciones de Manera Segura, sin ser Víctima de Ser Considerado Cómplice. 
Lic. Edwin Granados, EPLC Criminólogo, Profesional Especializado en Prevención del Fraude LD-FT del Sector Asegurador de San José - Costa Rica.

05:30 pm Prevenir el Lavado De Activos en el Mercado de Seguros-Experiencia Brasil.

Doctor Jair Jaloreto, Abogado en Derecho Penal Económico, Socio Fundador de Jaloreto \& Associados, Presidente de Lexnet-Law Firms Alliance - Brasil.

Jueves 17 - sección vespertina (DE 03:00 - 06:00 PM).

03:00 pm Panel: Pasos para Implementar una Perfecta Cultura de Mitigación de Riesgos. Identificación, Compromiso y Concientización.

Lic. Juan Pablo Rodríguez Cárdenas, Consultor Anti lavado, Anti Corrupción y Anti Soborno, CEO Socio Director de RICS Management - Colombia.

04:00 pm Uso de la Tecnología De FRISS en la Mitigación de Riesgos y Detección de Fraudes y Nuestra Aventura en América Latina. - Holanda.

Ingeniero Iván Ballón: Director de Negocios en Latino América y países ibéricos de FRISS.

04:45 pm Fraude 4.0 “El Nuevo Medio de Pagos Brasileño, Desafíos de Combate a Fraude”.

Dr. Marcio Malfatti, Ex-presidente de AIDA, Asociación Internacional de Directores de Seguros, Socio Presidente de la Firma Pimentel \& Asocs. Abogados - Brasil.

05:45 pm Sección de Preguntas y Respuestas - Lic. Dicla López - República Dominicana.

Viernes 18 - sección vespertina (DE 03:00 - 06:00 PM).

03:00 pm De Conozca a su Cliente, a Conozca su Riesgo. Identifique, Diagnostique, Mida, Controle, Mitigue y Monitoree.

Lic. Eliana Patricia Díaz, Encargada de Prevención de Lavado de Activos y Financiación del Terrorismo de la Superintendencia de Seguros de Rep. Dom. - Colombia.

04:00 pm El Riesgo de Colocación de Productos en el Mercado Asegurador como Factor de Riesgo del LA-FT y su Impacto en el Sistema Financiero.

Lic. Alba Lilian Jaramillo, Abogada con Especialización en Derecho Comercial y Financiero y Antifraude, Sales Compliance, Anti Money Laundry - Colombia.

05:00 pm El Riesgo inherente del negocio de seguros para la Banca (Banca-Seguros) Las. Actividades de las Aseguradora y que Riesgo le Genera a la Banca como Respaldo.

Lic. Karen Pivaral, Inspectora de la Intendencia de Verificación Especial UIF, Experta en supervisión de entidades financieras, Especialista en Administración de Negocios - Guatemala.

Sábado 19 - sección m a t u t i n a (09:00 am - 12:30 pm).

09:00 am Técnicas de Control de Riesgo Fraudes y Lavado de Activos en el Sector Asegurador (Caso Práctico). 
Lic. Rafiel Vásquez. Abogada Experimentada en la Industria de Seguros, Especialista.

Certificada en Leyes Internacionales y Negociación. - República Dominicana.

Lic. Vladimir Garrido, 09:45 am Visión Estratégica del Impacto de Delitos en Seguros desde una Mirada de la Aseguradora a partir de la Crisis del 2020.

Lic. Pablo Pin, Director Risk Management Consulting, Director en AON Reinsurance Solutions LATAM - Florida - Estados Unidos.

10:30 am Responsabilidad Civil Contractual y Extracontractual por mala Praxis Médica.

(Clientes, Abogados, Médicos, Centros Médicos, Hospitales, Farándula, y Compañías de Seguros).

Doctora Vanesa Di Cataldo, Doctora en Derecho, Especialista en Mala Praxis y Daños - Argentina.

11:30 am Sección de Preguntas y Respuestas - Lic. Luis Doval - Alemania.

12:00 pm Acto de Clausura y Entrega de Reconocimientos y Certificados.

\section{AEDSIA}

La Asociación para el estudio del Derecho de seguro del interior argentino llevó a cabo un ciclo internacional de conferencias invitando a miembros del CILA.

Juan Manuel Diazgranados -El impacto del COVID 19 en algunos seguros de Responsabilidad Civil-15 junio de 2020.

El CCN, elimino el daño moral, ¿y la sanción pecuniaria disuasiva? - Carlos Schiavo - 16 de junio de 2020 .

Derecho de los consumidores en tiempos de COVID-19 - 24 de junio de 2020.

Disertaciones a cargo de la Abg. Leticia Pelle Delgadillo y el Abg. Damián Vila. El Pasajero del transporte aéreo en tiempos de COVID-19 (Abg. Damián Vila) Precios cuidados (Abg. Leticia Pelle Delgadillo).

Jornadas nacionales - Waldo Sobrino - 24 de junio de 2020.

Marcelo Barreto Leal - Angélica Carlini - 7 de julio de 2020.

Seguros de caución - Maria José Arguello, Gastaldi y Ciabattoni.

"A cinco meses de la declaración de la pandemia: ¿Impactó realmente al mercado asegurador?"-Martin Argañaraz Luque - 2 de agosto.

\section{El esquema de enfermedades profesionales en el sistema lrt - 20 de agosto}

Todas estas conferencias pueden ser vistas en la página de Youtube de AEDSIA https://www.youtube.com/channel/UC-nHSGe94AHzqDnOMcmes6Q 
Necrológico. lamentamos comunicar el fallecimiento del Dr. Desiderio Sanabria Torres, destacado miembro de AIDA PARAGUAY Y EL CILA.

Agradecimiento. La Sección informativa de la Revista Ibero latinoamericana de Seguros agradece profundamente a todas las secciones nacionales del CILA, los grupos de trabajo y otras organizaciones académicas por el envío de sus reseñas que hacen de esta sección la memoria escrita de las actividades académicas en seguros.

La presente sección permite ver con auténtico orgullo la magnitud del trabajo académico de la región por lo que hacemos llegar la más sincera felicitación y reconocimiento a todos quienes hicieron posible la difusión del conocimiento y de la ciencia, como nunca en la historia, Es un privilegio reflejar tano trabajo de calidad en esta sección informativa.

\section{Sandra Ramírez}

Directora de la Sección informativa 
